\title{
Determinants and Solutions for Improving the Efficiency of Tourism Business
}

\author{
Nguyen Ngoc Tien*, Tran Thi Cam Thanh, Nguyen Thi Le Hang \\ Faculty of Economics \& Accounting, Quy Nhon University, Quy Nhon, Vietnam \\ Email address: \\ nguyenngoctien@qnu.edu.vn (N. N. Tien) \\ ${ }^{*}$ Corresponding author \\ To cite this article: \\ Nguyen Ngoc Tien, Tran Thi Cam Thanh, Nguyen Thi Le Hang. Determinants and Solutions for Improving the Efficiency of Tourism \\ Business. American Journal of Theoretical and Applied Business. Vol. 5, No. 1, 2019, pp. 14-19. doi: 10.11648/j.ajtab.20190501.12
}

Received: January 20, 2019; Accepted: March 14, 2019; Published: April 8, 2019

\begin{abstract}
Tourism is a combined business including four main fields: hotel business; eating and drinking; travelling and entertainment business. The efficiency of tourism business has the huge impact on many aspects of socioeconomic life but tourism business is also influenced by many factors because of tourism characteristics such as the seasonal in business, state and local policy, tourist resource, geographic position, etc. Hence, the objective of this study is to identify groups of factors that affect on the efficiency of tourism business. This is the basis for the authors to suggest solutions for improving the efficiency of tourism business. This study was conducted on the basis of survey questionnaires and interviews with 120 tourist enterprises in Binh Dinh, Phu Yen and Gia Lai in Vietnam about the evaluation perspective of enterprises for factors affecting tourism business efficiency. Data collected from enterprises is handled through SPSS 22.0 software. The results show that there are 6 groups of factors affecting the efficiency of tourism businesses.
\end{abstract}

Keywords: Determinants of Tourism Business, Tourism Business, Efficiency of Tourism Business

\section{Introduction}

This study is an experimental research of analysing the factors that affect on the business efficiency of the tourist enterprises surveyed typically in Binh Dinh, Phu Yen and Gia Lai. These factors are divided into factor groups affecting on the business efficiency by analysing the interrelation between them. This study also proposes some suitable solutions to improve the tourist business efficiency.

To do this research, the authors surveyed and chose 120 samples of tourist enterprises in Binh Dinh, Phu Yen and Gia Lai. The result had 98 valid responses, accounting for $81.66 \%$.

To make sure of the reliability of obtained results when they are analysed and verified, the authors examined the surveyed samples in the fulfilled, representive and comprehensive aspects by basing on the following criteria:

(1) In term the size of enterprise: the collected samples include the large, medium and small companies.

(2) In term of capital ownership: the collected samples contains both the state-owned and private enterprises.

(3) In term of legal responsibility: the collected samples consist of the joint-stock company; the limited liability company; the private company and others.

(4) In term of business field: the collected samples are in travelling; eating and drinking; staying and entertaining fields.

This study is designed to examine the effects of the characteristics of tourism on the business efficiency of the tourist enterprises. The study tries to answer the main questions:

(1) What are the factors affecting on the business efficiency of the tourist enterprises?

(2) What should be done to improve the business efficiency of the tourist enterprises?

\section{Literature Review}

Referring to factors affecting tourism business, there have a number of case studies in some countries which suggest that the following factors have a significant effect on tourism business performance, including: elements of policy such as macroeconomic policy of the state and micro-policy institutions of each locality (Dan and John, 2013) [1]; 
Seasonality in tourism business (Lee and Regena, 2003) [2]; Quality of human resources in the tourism and hospitality industry (Tom et al, 1997) [3]; Natural conditions such as climate, weather or geographic area (BelénGómez Martín, 2004) [4]; Convenience of tourism business (David et al, 2004) [5]; Transport infrastructure for tourism business (Jameel et al, 2007) [6]; Transportation facilities serve destinations (Bruce et al, 2000) [7]; Intangible cultural heritage and local customs (Wanda, 2010) [8] (Hien, 2014) [9]; local festivals (Leonard, 2008) [10], (Son, 2014) [11], (Hien, 2014) [12]; Business environment (Tien, 2012) [13]. The drawback of these studies is to consider and evaluate the factors affecting business activities according to each individual factor while the effectiveness of tourism business is affected by many factors at the same time and highly depends on the tourism development policy of each locality.

From the overview of the above studies, we suppose that there are some groups of factors affecting the efficiency of tourism business such as State policy, Local policy, External business environment, Investment status, enterprise' human source, Natural condition, geographic area, Socioeconomic condition, Infrastructure, Means of transport, Local custom and culture, The seasonal in business, Annual events.

\section{Research Methods}

\subsection{Research Design}

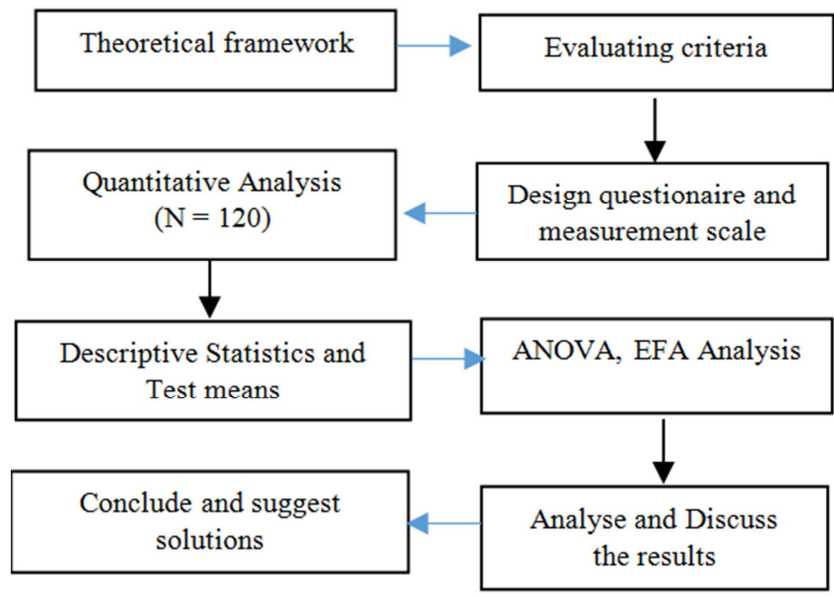

Figure 1. Studying process.

The research design is influenced by the questionaire and purpose of the study. The descriptive statistics; test means; analysis of variance (Anova); exploratory fator analysis (EFA) are used in this study. The aim of descriptive statistics and test means is to summarize the data, describe collected samples in numbers or graphs. This helps us have an overall view of the real effects of factors to business efficiency. The Anova and EFA analysis show that the interrelationship between factor groups has the huge impact on tourism business efficiency (Hoang, Chu, 2011) [14]. The combination between these methods in analysing and testing data helps us get the objective results- the base of suggesting the solutions.

\subsection{Gathering Data}

\section{Data Resource:}

Methods of investigation and taking the expert advice was used. The authors designed the investigating questionaire to collect ideas of the top and middle level managers in the tourist enterprises. The authors also interviewed directly the experts in tourism, such as: state managers; scientists; lowlevel managers in the tourist companies in Binh Dinh, Phu Yen and Gia Lai.

Gathering Data Subject:

The authors used method of choosing convenient samples in two main subject groups:

(1) The first group: the tourist enterprises in Binh Dinh, Phu Yen and Gia Lai.

(2) The second group: the experts in tourism: state managers, business managers, scientists.

\section{Gathering Data Mode:}

Two main modes of gathering data are collecting directly and sending the questionaire to the tourist enterprises by Google Docs. Besides, the authors carried out interviewing the experts, managers and scientists in tourism.

\section{Gathering Data Media:}

The designed questionaire is the main medium to collect data. The official questionaire is designed by three steps:

Step 1: Designing the draft

Step2: The draft is consulted by the professional experts.

Step 3: Designing the official questionaire.

Because the questionaire is concentrated on evaluating the impact level of determinants, it is designed to collect the following information:

Part 1: The general information of enterprises

In this part, the general information of enterprises is collected: operating period, business field, number of labour, the size of company, legal responsibility...

Part 2: The determinants of the tourism business efficiency

This part concentrates on determinants, such as: policy institution, business environment, infrastructure, human source in tourism, geographic position, festival, tourist security, tourist services, etc.

The purpose of the questions in this part is to collect information of determinants of the business efficiency in the tourist enterprises. By analysing these factors, this study also proposes some solutions and petitions for policy makers to improve the tourism business efficiency.

To support for the survey research, the Likert scale (5 choices) is used. The format of five-level Likert scale is: $1=$ "very low"; 2= "low"; 3 = "medium"; 4 = "high"; 5 = "very high".

\subsection{Analysing Data Technique}

There are total of 98 collective and valid responses. After collecting data, according to the part and the group of these data in the questionaire, they are changed and encoded in Microsoft Excel. Then, SPSS 22.0 is applied to analyse these data, in detail:

Sample Statistics: 
Sample Statistics is used to count and calculate the percentage of sample in evaluating criteria and classifications...

Descriptive Statistics and Test the average value (mean):

The mean of determinants is calculated by the descriptive statistics while to evaluate the influence level of the factors, these means are compared with 3- the total average level.

\section{Anova Analysis:}

Anova analysis is used to compare the means of groups. In this study, the size of business is divided into four groups: large, medium, small and supersmall enterprises. By Anova analysis, the authors will examine: whether there is the difference in the means between these groups or not? If yes, which groups will have this difference.

Exploratory Factor Analysis (EFA):

When applying EFA analysis, researchers often pay attention to some criteria: Firstly, KMO coefficient $\geq 0.5$, significance level in Bartlett- Test: $\alpha \leq 0.05$. KMO (KaiserMeyer-Olkin) measures the adequacy of sample. If $0.5 \leq$ $\mathrm{KMO} \leq 1$, the sample is adequate. Bartlett-Test examine the hypothesis that the correlation coefficient is zero. If this test has the statistic significance ( $\mathrm{Sig} \leq 0.05$ ), there is the correlation between variables. Secondly, the factor loading coefficient (factor loading) $>0.45$. If the factor loading of observed variable $\leq 0.45$, it will be eliminated (Ho D. P, Nhi V. V, Phuoc T., 2018) [15]. Thirdly, measurement scale is accepted when sum of extracted variance $\geq 50 \%$ and eigenvalue is greater than 1. Finally, to ensure the discriminating value between factors, the factor loading of an observed variable in factors is greater than 0.3 . The factor loading is used to ensure practical significance of EFA analysis. Factor loading $>0.3$ is minimum value; factor loading $>0.4$ is important and $\geq 0.5$ is practical significance.

\section{Result of Research}

\section{Determinant Analysis:}

To verify analysis, first of all, the authors analysed descriptive statistic, the means of factors is from 3.2 to 4.8 . This shows that all of factors: state policy, local policy, business environment, investment status\& enterprise' human source, natural condition and geographic area, socioeconomic condition, infrastructure, the seasonal in business have the influence on business efficiency of the tourist business.

To know how these factors affect on business efficiency, the authors carried out verifying influence level of these factors by calculating the means and verifying that is the means $(\mu)$ greater than 4 ? (4 is high influence level, approximately 5 is very high)

Hypotheses of test:

$\mathrm{H}_{0}: \mu=4$

$\mathrm{H}_{1}: \mu \neq 4$

The result of T-test:

Table 1. The result of T-test in analysing influence level of factors to business efficiency.

\begin{tabular}{|c|c|c|c|c|c|c|}
\hline \multirow{3}{*}{ One-Sample Test } & \multicolumn{6}{|c|}{ Test Value $=4$} \\
\hline & \multirow{2}{*}{ t } & \multirow{2}{*}{ df } & \multirow{2}{*}{ Sig. (2-tailed) } & \multirow{2}{*}{ Mean Difference } & \multicolumn{2}{|c|}{ 95\% Confidence Interval of the Difference } \\
\hline & & & & & Lower & Upper \\
\hline State policy & -8.796 & 98 & .000 & -.65039 & -.7961 & -.5036 \\
\hline Local policy & 1.157 & 98 & .251 & .07767 & -.0555 & .2109 \\
\hline External business environment & -11.901 & 98 & .000 & -.70874 & -.8269 & -.5906 \\
\hline Investment status, enterprise' human source & .000 & 98 & 1.000 & .00000 & -.1341 & .1341 \\
\hline Natural condition, geographic area & 2.931 & 98 & .004 & .19417 & .0628 & .3256 \\
\hline Infrastructure & 18.863 & 98 & .000 & .79615 & .7126 & .8788 \\
\hline Means of transport & 21.267 & 98 & .000 & .83495 & .7571 & .9128 \\
\hline Local custom and culture & -8.995 & 98 & .000 & -.52427 & -.6399 & -.4087 \\
\hline The seasonal in business & 1.112 & 98 & .270 & .07767 & -.0610 & .2164 \\
\hline Annual events & -11.043 & 98 & .000 & -.78641 & -.9279 & -.6443 \\
\hline
\end{tabular}

The result of verifying factors is in Sig. column (2-tailed): $\mathrm{Sig}<5 \%$ means that with the significance level 5\% (trust level 95\%), we reject $\mathrm{H}_{0}$, accept $\mathrm{H}_{1}$; $\mathrm{Sig}>$ $5 \%$ means that there is not enough basis to reject $\mathrm{H}_{0}$.

The result table shows that:

The Sig values of factors: local policy institution; investment status and enterprise' human source; the seasonal in business are greater than 0.05 . It means that we have not enough basis to reject $\mathrm{H}_{0}$. The means of these variables are 4, it shows that the influence level of these factors is high.

The Sig values of factors: natural condition; geographic area is less than 0.05 . The means of these factors is greater than 4 (the gap between the mean with 4 is about 0.19 ), it shows that these factors have a high influence level to the business efficiency. By contrast, although the infrastructure; means of transport also have Sig values smaller than 0.05 , the average value of these factors is much greater than 4 (the gap is 0.796 and 0.834 , respectively). It means that these factors has a very high influence level to business efficiency of the tourist enterprises.

While that, with the mean is smaller than 4 and Sig value is smaller than 0.05 (the gap is less than 0), other remaining factors has the average influence level.

Conclusion, the tourism business efficiency is infuenced by both internal and external factors of enterprise. So, which factors have the same importance to business efficiency? To tackle this problem, the authors used EFA analysis and correlation analysis.

EFA Analysis:

Because the exploratory factor analysis requires the 
intercorrelation between factors, the authors carried out

The result of correlation between determinants test: correlation test and variance test.

Table 2. The result of correlation between determinants test.

\begin{tabular}{lll}
\hline KMO and Bartlett's Test & & \\
\hline Kaiser-Meyer-Olkin Measure of Sampling Adequacy & Approx. Chi-Square & .626 \\
& df & 526.149 \\
Bartlett's Test of Sphericity & Sig. & 98 \\
& & .000 \\
\hline
\end{tabular}

From the result, with $\mathrm{KMO}=0.626(>0.5)$, we reject the hypothesis that correlation matrix is homogeneous matrix. It means that the variables are intercorrelated and satisfy the condition in EFA analysis.

The result of extracted variance analysis:

Table 3. The result of extracted variance analysis of determinant group.

\begin{tabular}{llllllllll}
\hline \multirow{2}{*}{ Component } & \multicolumn{2}{l}{ Initial Eigenvalues } & \multicolumn{3}{c}{ Extraction Sums of Squared Loadings } & \multicolumn{3}{l}{ Rotation Sums of Squared Loadings } \\
\cline { 2 - 9 } & Total & \% of Variance & Cumulative \% & Total & \% of Variance & Cumulative \% & Total & \% of Variance & Cumulative \% \\
\hline 1 & 3.720 & 21.883 & 21.883 & 3.720 & 21.883 & 21.883 & 2.458 & 14.461 & 14.461 \\
2 & 2.002 & 11.775 & 33.658 & 2.002 & 11.775 & 33.658 & 2.224 & 13.083 & 27.544 \\
3 & 1.775 & 10.440 & 44.097 & 1.775 & 10.440 & 44.097 & 1.830 & 10.767 & 38.311 \\
4 & 1.583 & 9.313 & 53.410 & 1.583 & 9.313 & 53.410 & 1.829 & 10.761 & 49.072 \\
5 & 1.415 & 8.323 & 61.733 & 1.415 & 8.323 & 61.733 & 1.807 & 10.631 & 59.703 \\
6 & 1.062 & 6.244 & 67.977 & 1.062 & 6.244 & 67.977 & 1.407 & 8.275 & 67.977 \\
\hline
\end{tabular}

The extracted variance analysis table shows that with eigenvalue $>1$, there are only 6 factors extracted. With fluctuating value is 67.977 , it means that the fluctuation of figures is explained by 6 new factors.

The exploratory factor group analysis table:

Table 4. The result of exploratory factor group analysis.

\begin{tabular}{|c|c|c|c|c|c|c|}
\hline \multicolumn{7}{|l|}{ Rotated Component Matrix ${ }^{a}$} \\
\hline & \multicolumn{6}{|c|}{ Component } \\
\hline & 1 & 2 & 3 & 4 & 5 & 6 \\
\hline Natural landscape & & & & .651 & & \\
\hline Climate, weather & & & & & & .899 \\
\hline Local geographic position & & & & .545 & & .459 \\
\hline Infrastructure and means of transport & & & -.782 & & & \\
\hline Traditional trade village, fine arts & .489 & & & .457 & -.418 & \\
\hline Folk festival/fair & & .722 & & & & \\
\hline Staying/Relaxing place & & & & .786 & & \\
\hline Restaurant \& food diversification & & .739 & & & & \\
\hline Prepared tours & .526 & & & & & \\
\hline Entertainment services & .495 & .435 & & & & \\
\hline Shopping Centers and Souvenir shops & & .737 & & & & \\
\hline Price and service fees & .838 & & & & & \\
\hline Quality of related services (bank, health,...) & & & & & .791 & \\
\hline Friendliness of natives & & & .744 & & & \\
\hline Social security & .729 & & & & & \\
\hline Night' activities & & & & & .816 & \\
\hline
\end{tabular}

Along with three main determinants: local policy; investment status\& enterprise' human source and the seasonal in tourism business, there are other determinants of business efficiency. They are divided into 6 groups:

Group 1: it includes variables: (1) Prepared tours, (2) Price and service fees, (3) Social security. For (1) Traditional trade village and fine arts, (2) Entertainment services, they can be sorted in group 1 because their loading coefficient (the mathematic term for figures in this analysis table) is at the highest level as they are in this group. However, because of these values are smaller than 0.5, two factors have the insignificant influence.
Group 2: (1) Folk festival/fair, (2) Restaurant\& food diversification, (3) Shopping centers, souvenir shops.

Group 3: (1) Infrastructure and means of transport, (2) Friendliness of natives.

Group 4: (1) Natural landscape, (2) Local geographic position, (3) Staying/relaxing place.

Group 5: (1) Quality of related services (bank, health...) and (2) Night's activities.

Group 6: Climate and weather.

The result of verifying in Anova analysis for exploratory factor groups shows that the large, medium, small and supersmall enterprises have the same evaluating score for the 
third, fifth and sixth groups. By contrast, this score for the first, second and fourth group is different.

Conclusion, finding out factors and exploratory factor groups that influence on the business efficiency is the important basis to suggest solutions for improving tourism business efficiency.

\section{Solutions for Improving Tourism Business Efficiency}

Based on the research result, the authors propose the following solutions to improve tourism business efficiency. They consist of the solutions for tourist enterprises and petitions for policy makers formulating policies to foster the development of tourism.

Firstly, because local policy has the huge impact on the tourism business efficiency, the people's committees should concentrate on promulgating preferential policies to attract investment in tourism. Some policies can be mentioned: shortenning the licensing time of advantageous tourist fields; advertising local tourism and preferential policies for investment actively, permitting private enterprises to invest in the local major tourist destinations; extending nigh's time of tourism business; investing tourist infrastructure; promulgating convenient policies to create value chain for tourism services between provinces, such as: exploration tourism, leisure tourism, ecotourism, cultural tourism,...

Secondly, to improve the quality of human source of tourism, government should invest more in the universities training tourism. Beside that, these universities should form practical training programmes that help students get professional skills before entering the labour market. These universities also need to establish relationship with the domestic and international academic institutions to innovate their training programme.

Thirdly, to stabilize and attract more tourists everyyear, the tourism enterprise needs invest and upgrade its material facilities. It also needs to innovate and diversify its services and style of serving tourists. Particularly, the enterprise should concentrate on establishing cultural environment in business as well as training knowledge, practical skills for its employees. Beside that, there should be the relationship between the tourism enterprises to establish special tourist value chain.

Fourthly, although there are many annual festivals at localities, these festivals are quite small that causes difficulties in attracting tourists. So, local government should choose the most special festivals to invest and develop to national and international festivals. This helps localities attract more tourists as well as advertises local cultures to all people over the world.

Fifthly, to diversify tours, local government should concentrate on discovering and developing new tourist destinations, redesigning suitably trade villages network and tourist destinations as well.
Finally, the related services should be developed to serve demands of tourists, especially, the space for nigh' entertainment destinations should be cared.

\section{Conclusion}

The efficiency of tourism business of surveyed enterprises is influenced by many internal and external factors such as Prepared tours, Price and service fees, Social security, Folk festival/fair, Restaurant \& food diversification, Shopping Centers and Souvenir shops, Infrastructure and means of transport, Friendliness of natives, Natural landscape, Local geographic position, Staying/Relaxing place, Climate, weather, etc. Therefore, to develop tourism business, there should be the coordination between the tourist enterprises and local government in policies. The above petitions are suggested to ensure stable development of the tourism enterprises. This plays an important role in local advertising, income of local budget and solving local unemployed, socialeconomic problems.

\section{References}

[1] Dan Wang, John Ap (2013). Factors affecting tourism policy implementation: A conceptual framework and a case study in China, Tourism Management, Vol: 36, p. 221-233.

[2] Lee Jolliffe, Regena Farnsworth, (2003) "Seasonality in tourism employment: human resource challenges", International Journal of Contemporary Hospitality Management, Vol. 15 Issue: 6, pp. 312-316.

[3] Tom Baum, Vanessa Amoah, Sheryl Spivack, (1997) "Policy dimensions of human resource management in the tourism and hospitality industries", International Journal of Contemporary Hospitality Management, Vol. 9 Issue: 5/6, pp. 221-229.

[4] Belén Gómez Martín (2005). Weather, climate and tourism a geographical perspective, Annals of Tourism Research, Vol: 32, Issue 3, P. 571-591.

[5] David W. M, Kwang K. K, Steven C. D (2004). Natural amenities, tourism and income distribution, Annals of Tourism Research, Vol: 31, Issue 4, 2004, P. 1031-1050.

[6] Jameel K., Boopen S. (2007). Transport infrastructure and tourism development, Annals of Tourism Research, Vol: 34, Issue 4, P. 1021-1032.

[7] Bruce Prideaux (2000). The role of the transport system in destination development, Tourism Management, Vol: 21, issue 1, p. 53-63.

[8] Wanda George E. (2010). "Intangible cultural heritage, ownership, copyrights, and tourism", International Journal of Culture, Tourism and Hospitality Research, Vol. 4 Issue: 4, pp. 376-388.

[9] Hien N. P (2014), Exploiting the culture of religious beliefs in tourism development in the South Central region, Conference proceedings: Tourism development in the central coastal region associated with the Central Highlands , pp. 117-128.

[10] Leonard A. Jackson (2008). "Residents' perceptions of the impacts of special event tourism", Journal of Place Management and Development, Vol. 1 Issue: 3, pp. 240-255. 
[11] Son T. D. A (2014). Linking Central Coast with Central Highlands in tourism development: from ethnic cultural perspective, Conference proceedings: Tourism development in the central coastal region associated with the Central Highlands, pp. 51-62.

[12] Hien N. D, Phuong H. T. M (2014), The issue of preserving the cultural value of the Central Highlands's gong in tourism activities, Conference proceedings: Tourism development in the central coastal region associated with the Central Highlands, pp. 109-115.
[13] Tien N. N (2012). Tourism business characteristics influence on analysing business efficiency, Auditing Study Journal, Vol: $50+51$, pp. $51-53$

[14] Hoang, T., Chu, M. N. (2011). Applied Statistics in SocialEconomic Analysis. Labour and Social Publising House. Ha Noi.

[15] Ho D. P, Nhi V. V, Phuoc T. (2018). Quantitative research in Accounting - Auditing. Financial Publishing House, Ha Noi. 